\title{
History of Paroxysmal, Persistent, Long-Standing or Permanent Atrial Fibrillation in Patients Undergoing Transcatheter Mitral Valve Repair with Mitraclip: Does it Matter?
}

\author{
Arturo Giordano $^{1^{*}}$, Ciro Indolfi ${ }^{2}$, Cesare Baldi ${ }^{3}$, Paolo Ferraro ${ }^{1}$, Filippo Finizio ${ }^{1}$, Nicola \\ Corcione $^{1}$, Michele Polimeno ${ }^{1}$, Stefano Messina ${ }^{1}$, Annalisa Mongiardo ${ }^{2}$, Giuseppe Biondi- \\ Zoccai $^{4,5}$, Massimo Mancone ${ }^{6}$, Raffaella Avellino ${ }^{1}$ and Gennaro Sardella ${ }^{6}$ \\ ${ }^{1}$ Unità Operativa di Interventistica Cardiovascolare, Presidio Ospedaliero Pineta Grande, Castel Volturno, and Unità \\ Operativa di Emodinamica, Casa di Salute Santa Lucia, San Giuseppe Vesuviano, both in Italy \\ ${ }^{2}$ Division of Cardiology, Department of Medical and Surgical Sciences, University Magna Graecia, Catanzaro, Italy \\ ${ }^{3}$ Division of Cardiology, S. Giovanni di Dio-Ruggi d'Aragona Hospital, Salerno, Italy \\ ${ }^{4}$ Department of Medico-Surgical Sciences and Biotechnologies, Sapienza University of Rome, Latina, Italy \\ ${ }^{5}$ VCU Pauley Heart Center, Richmond, VA, USA \\ ${ }^{6}$ Department of Cardiovascular and Pulmonary Sciences, Policlinico Umberto I, Sapienza University of Rome, Italy
}

Received: January 30, 2015; Accepted: March 05, 2015; Published: March 15, 2015

*Corresponding author: Arturo Giordano, Unità Operativa di Interventistica Cardiovascolare, Presidio Ospedaliero Pineta Grande, Strada Statale Domiziana Km 30, 81030 Castel Volturno, Italy. Tel: +39082385438; Fax: +390823854151; E-mail: arturogiordano@tin.it

\begin{abstract}
Background: Atrial Fibrillation (AF) may impact adversely on mitral valve function. Transcatheter Mitral Valve Repair (TMVR) with MitraClip is considered an acceptable alternative to surgical repair in high risk patients, and the EVEREST II trial has suggested that this holds true even in patients with AF. However, there is uncertainty on the outlook of real-world patients with AF undergoing TMVR.

Methods: We analyzed retrospectively collected data on patients undergoing TMVR at 3 tertiary care centers. Baseline, procedural, and outcome details were systematically sought. Patients were followed after discharge for clinical events and echocardiographic changes.

Results: A total of 116 subjects were included: 61 (53\%) with $\mathrm{AF}$ and $55(47 \%)$ without AF. Patients with AF had worse baseline functional class and EuroSCORE II, and a higher prevalence of type II mitral regurgitation, but patients without AF had higher prevalence of dilated or ischemic cardiomyopathy and of severe mitral regurgitation (all $p<0.05$ ). Procedural success was achieved in most patients $(115$ [99\%]) with out any differences according to the history of AF, but multiple MitraClips were required more frequently in patients with $\mathrm{AF}(\mathrm{p}=0.031)$. Echocardiographic and clinical results at follow-up were also similarly favorable, with $4(3 \%)$ in-hospital deaths and a total of $15(13 \%)$ at follow-up. However, patients with AF had a higher incidence of the composite of death or rehospitalizations for heart failure (14 [34\%] vs 5 [13\%], $p=0.035$ ). Differences were not especially pronounced when focusing on patients with longstanding/ permanent $\mathrm{AF}$ vs those with paroxysmal/persistent $\mathrm{AF}$.
\end{abstract}

Conclusions: Despite largely similar baseline, echocardiographic and procedural features, patients with AF undergoing TMVR with MitraClip may face a higher risk of adverse events during follow-up. Careful follow-up and medical management are thus mandatory in such patients, irrespective of the subtype of AF.

Keywords: Atrial fibrillation; Heart failure; MitraClip; Mitral regurgitation; Mitral valve repair

\section{Introduction}

Mitral regurgitation is associated with an unfavorable clinical impact when symptoms or signs of adverse cardiac remodeling become evident [1]. Whereas surgical repair remain the reference treatment in most patients, subjects at high operative risk and suitable valve features may benefit from transcatheter mitral valve repair (TMVR) with the MitraClip device [2]. Favorable results have been reported in pivotal clinical trials and observational registries for MitraClip, but the evidence base is still incomplete and requiring progressive accrual [1-5].

The main and obvious limitation of MitraClip lies in its focus only on leaflets, and the lack of impact on annulus anatomy and function. Indeed, the mitral annulus is a dynamic structure which has a major pathophysiologic role in mitral regurgitation [6]. However, MitraClip remains clinically appealing given its limited invasiveness and relative user-friendliness.

This is particularly relevant in patients with atrial fibrillation in whom MitraClip is envisioned. Atrial fibrillation has indeed detrimental effects of the highly complex and dynamic changes in mitral annulus during the cardiac cycle, such that restoration of sinus rhythm is associated with improvements in mitral regurgitation degree in patients with paroxysmal or transiently persistent but eventually treatable atrial fibrillation [7-9]. On the other hand, patients with permanent (i.e. chronic) atrial fibrillation undergoing MitraClip implantation may be at higher risk of procedural failure, peri-procedural complications, or suboptimal results during follow-up. Recently, patients with atrial fibrillation enrolled in the pivotal EVEREST II trial were shown to have more diseased valves and multiple comorbidities, 
but the comparative safety and efficacy of MitraClip was not worse in them [10]. Yet, this study did not distinguish according to the subtype of atrial fibrillation and may have limited external validity.

We thus aimed to appraise the immediate and midterm impact of history of atrial fibrillation, distinguishing pragmatically according to subtypes, in patients undergoing TMVR with MitraClip.

\section{Methods}

This work is a retrospective multicenter registry. As previously described elsewhere, patients were included in the registry if undergoing MitraClip implantation for significant (at least moderate) mitral valve regurgitation, irrespective of valve anatomy or cardiac condition [11]. Subjects were considered eligible according to each specific institution standard of practice, but in general only patients deemed at high surgical risk after heart team evaluation were considered suitable candidates for TMVR. In addition, only subjects with valve anatomy suitable for MitraClip implantation were referred for such procedure.

MitraClip implantation was performed by experienced operators under general anesthesia and through fluoroscopic and transesophageal echocardiography (TEE) guidance, as reported elsewhere [11]. MitraClip implantation was performed according to established protocols after having accessed the right femoral vein with a 24 French sheath and successful trans-septal puncture. All MitraClip implantations were attempted with the standard central clip concept (a single MitraClip is implanted and the results appraised with TEE, with additional MitraClip implantations performed only as bailout in case of suboptimal results). At the end of the procedure patients were weaned and subsequently extubated and then monitored for at least 24 hours. Subjects without an indication for oral anticoagulants (e.g. atrial fibrillation at significant risk for thromboembolism) continued aspirin plus clopidogrel for 1 month followed by aspirin alone for additional 2 months. Patients with an indication to oral anticoagulation were instead managed with oral anticoagulants alone, unless aspirin was indicated also for coronary artery disease.

Control Trans-Thoracic Echocardiography (TTE) was performed before discharge, 1 month, 3 months, and 6 months after the indeed procedure, with subsequent follow-up exams every 6-12 months. Clinical follow-up was performed at the same time intervals by office visit or phone contact, if TTE had been performed elsewhere.

Outcomes of interest were procedural success (successful clip implantation with residual mitral regurgitation grade $\leq 2+$ ), total hospital stay, and in-hospital events (death, myocardial infarction, major bleeding or acute kidney injury). In addition, we appraised the occurrence during follow-up of death, myocardial infarction, stroke, mitral valve surgery, rehospitalizations after successful discharge, mitral regurgitation grade, and New York Heart Association class. For the purpose of this work focusing on atrial fibrillation, and in keeping with current guidelines, we distinguished atrial fibrillation in the following subtypes: paroxysmal (lasting up to 7 days), persistent (lasting more than 1 week but less than 1 year, or requiring termination by cardioversion), long-standing persistent (lasting for at least 1 year), and permanent (when the presence of the arrhythmia is accepted by the patient and physician).

Descriptive analyses were based on counts (\%) for categorical variables and median ( $11^{\text {st }}-3^{\text {rd }}$ quartile) for continuous variables. Inferential analysis was based on bivariate analyses using Fisher exact tests for categorical variables and Kruskal-Wallis U test for continuous variables. Statistical significance was set at the 2-tailed 0.05 level. Computations were performed with Stata 13 (StataCorp, College Station, TX, USA).

\section{Results}

A total of 116 patients were included: 55 (47.4\%) in sinus rhythm and 61 (52.6\%) with atrial fibrillation. Specifically, out of the 61 subjects with atrial fibrillation, $11(18.0 \%)$ had paroxysmal, 7 (11.5\%) persistent and 43 (70.5\%) long-standing/permanent atrial fibrillation. Accordingly, patients with paroxysmal and persistent atrial fibrillation were grouped together to maximize comparative precision and accuracy.

Baseline features are reported in Table 1. Patients with atrial fibrillation were similar to those without atrial fibrillation for most characteristics, with the notable exception of dilated or ischemic cardiomyopathy, which were more common in subjects without atrial fibrillation (respectively 23 [41.8\%] and 25 [45.5\%] vs 27 [32.9\%] and 21 [25.6\%] in those with atrial fibrillation, $p=0.016$ ), baseline prevalence of New York Heart Association class IV, which was more common in patients with atrial fibrillation $(21$ [34.4\%] vs 7 [12.7\%] in subjects without atrial fibrillation, $p=0.009$ ) and EuroSCORE II, which was higher in patients with long-standing/permanent atrial fibrillation (11.5\% [2.5\%; 28.6\%] vs $2.7 \%$ [1.7\%; $8.1 \%]$ in those with paroxysmal/persistent atrial fibrillation vs $4.4 \%$ [2.1\%; $14.7 \%$ ] in those without atrial fibrillation, $p=0.015$ ).

Baseline echocardiographic and procedural features are presented in Table 2. Most characteristics were similar in the study groups. However, patients without atrial fibrillation had a higher prevalence of severe mitral regurgitation (42 [76.4\%] vs 11 [61.1\%] in those with paroxysmal/persistent atrial fibrillation vs 25 [58.1\%] in those with long-standing/permanent atrial fibrillation, $p=0.013$ ). Conversely, type II mitral regurgitation according to the Carpentier classification (i.e. excessive leaflet motion) was more common in patients with atrial fibrillation (16 [26.2\%] vs 5 [9.1\%] in those without atrial fibrillation, $p=0.028$ ).

Procedural success occurred overall in 115 (99.1\%) subjects, without differences according to history of atrial fibrillation. However, patients with atrial fibrillation required more commonly the implantation of multiple MitraClips (24 [39.3\%] vs 17 [30.9\%] in those without atrial fibrillation, $p=0.031$ ). Echocardiographic results at a median follow-up of 6 months were also similar irrespective of the presence or absence of atrial fibrillation (Table 3), with most (105 [90.5\%]) patients showing a 
Table 1: Baseline clinical features according to the presence and subtype of atrial fibrillation (AF).

\begin{tabular}{|c|c|c|c|c|c|c|}
\hline & $\begin{array}{c}\text { No AF } \\
(N=55)\end{array}$ & $\begin{array}{l}\text { Any AF } \\
(\mathrm{N}=61)\end{array}$ & $\begin{array}{c}\text { Paroxysmal/persistent } \\
\text { AF } \\
(\mathrm{N}=18)\end{array}$ & $\begin{array}{l}\text { Long-standing/ } \\
\text { Permanent AF } \\
\quad(\mathrm{N}=43)\end{array}$ & $\mathbf{P}^{*}$ & $\mathrm{P}+$ \\
\hline Age (years) & $74.1(67.5 ; 78.8)$ & $75.8(71.5 ; 79.2)$ & $72.3(70.0 ; 79.8)$ & $76.3(73.5 ; 79.2)$ & 0.147 & 0.146 \\
\hline Body mass index & $25.9(24.0 ; 27.9)$ & $25.0(22.9 ; 27.3)$ & $26.7(23.0 ; 28.8)$ & $24.9(22.9 ; 27.2)$ & 0.331 & 0.202 \\
\hline Female sex & $30(54.6 \%)$ & $29(47.5 \%)$ & $6(33.3 \%)$ & $23(53.5 \%)$ & 0.464 & 0.262 \\
\hline Hypertension & $35(63.6 \%)$ & $40(65.6 \%)$ & $13(72.2 \%)$ & $27(62.8 \%)$ & 0.848 & 0.809 \\
\hline Diabetic status & & & & & 0.071 & 0.113 \\
\hline Non-diabetic & $34(61.8 \%)$ & 47 (77.1\%) & $14(77.8 \%)$ & $33(76.7 \%)$ & & \\
\hline Non-insulin-dependent diabetic & $19(35.6 \%)$ & $10(16.4 \%)$ & $4(22.2 \%)$ & $6(14.0 \%)$ & & \\
\hline Insulin-dependent diabetic & $2(3.6 \%)$ & $4(6.6 \%)$ & 0 & $4(9.3 \%)$ & & \\
\hline Prior myocardial infarction & $31(56.4 \%)$ & $23(37.7 \%)$ & $7(38.9 \%)$ & $16(37.2 \%)$ & 0.062 & 0.124 \\
\hline $\begin{array}{l}\text { Prior pace-maker, ICD or CRT } \\
\text { implantation }\end{array}$ & & & & & 0.016 & 0.064 \\
\hline No & $40(74.1 \%)$ & $35(64.8 \%)$ & $13(72.2 \%)$ & $22(61.1 \%)$ & & \\
\hline Pace-maker & $1(1.9 \%)$ & $10(18.5 \%)$ & $2(11.1 \%)$ & $8(22.2 \%)$ & & \\
\hline ICD & $9(16.7 \%)$ & $8(14.8 \%)$ & $3(16.7 \%)$ & $5(13.9 \%)$ & & \\
\hline CRT $( \pm$ ICD) & $4(7.4 \%)$ & $1(1.9 \%)$ & 0 & $1(2.8 \%)$ & & \\
\hline Cardiomyopathy & & & & & 0.016 & 0.005 \\
\hline No & $7(12.7 \%)$ & $34(41.5 \%)$ & $10(43.5 \%)$ & $24(40.7 \%)$ & & \\
\hline Dilated & $23(41.8 \%)$ & $27(32.9 \%)$ & $8(34.8 \%)$ & $19(32.2 \%)$ & & \\
\hline Ischemic & $25(45.5 \%)$ & $21(25.6 \%)$ & $5(21.7 \%)$ & $16(27.1 \%)$ & & \\
\hline AF subtype & & & & & $<0.001$ & $<0.001$ \\
\hline None & $55(100 \%)$ & 0 & 0 & 0 & & \\
\hline Paroxysmal & 0 & $11(18.0 \%)$ & $11(61.1 \%)$ & 0 & & \\
\hline Persistent & 0 & $7(11.5 \%)$ & $7(38.9 \%)$ & 0 & & \\
\hline Long-standing/permanent & 0 & $43(70.5 \%)$ & 0 & $43(100 \%)$ & & \\
\hline New York Heart Association class IV & $7(12.7 \%)$ & $21(34.4 \%)$ & $6(33.3 \%)$ & $15(34.9 \%)$ & 0.009 & 0.021 \\
\hline $\begin{array}{l}\text { Chronic obstructive pulmonary } \\
\text { disease }\end{array}$ & $15(27.3 \%)$ & $16(26.2 \%)$ & $1(5.6 \%)$ & $15(34.9 \%)$ & 1.0 & 0.054 \\
\hline EuroSCORE II (\%) & $\begin{array}{l}\text { 4.4\% (2.1\%; } \\
\quad 14.7 \%)\end{array}$ & $\begin{array}{l}7.6 \%(2.4 \% \\
22.3 \%)\end{array}$ & $2.7 \%(1.7 \% ; 8.1 \%)$ & $11.5 \%$ (2.5\%; 28.6\%) & 0.397 & 0.015 \\
\hline Society of Thoracic Surgery score (\%) & $\begin{array}{l}5.0 \%(2.5 \% \\
11.0 \%)\end{array}$ & $\begin{array}{l}6.7 \%(3.9 \% \\
17.2 \%)\end{array}$ & $5.4 \%(2.6 \% ; 13.9 \%)$ & $9.6 \%(4.1 \% ; 20.2 \%)$ & 0.077 & 0.061 \\
\hline
\end{tabular}

*No AF versus any AF; †No AF versus paroxysmal/persistent AF vs permanent AF; $C R T=c a r d i a c$ resynchronization therapy; ICD=implantable cardioverter defibrillator

sustained decrease in mitral regurgitation degree in comparison to baseline.

Clinical outcomes were similarly favorable both in-hospital and at follow-up (Table 4) in light of the high risk features of the patients, with $4(3.4 \%)$ in-hospital deaths and a cumulative case fatality of $15(12.9 \%)$ cases. No safety issue appeared when comparing short- or mid-term outcomes according to history of atrial fibrillation, with the notable exclusion of the composite of death or rehospitalizations for heart failure, which more common in patients with atrial fibrillation (14 [34.2\%] vs 5 [12.8\%], $p=$ 0.035 ) (Figure 1). All deaths were due to non-cardiac causes, in keeping with the high risk features of included subjects.

In most cases, differences in baseline, procedural, and follow- up characteristics were not especially pronounced when focusing on patients with longstanding/permanent atrial fibrillation vs those with paroxysmal/persistent atrial fibrillation (Tables 1,2,3, and 4).

\section{Discussion}

This work, originally reporting on the comparative safety and efficacy of TMVR with the MitraClip device in patients with or without atrial fibrillation and distinguishing according to subtype of atrial fibrillation, suggests that despite largely similar baseline, echocardiographic and procedural features, patients with atrial fibrillation undergoing MitraClip implantation may face a higher risk of adverse events during follow-up. 
Table 2: Baseline echocardiographic and procedural features according to the presence and subtype of atrial fibrillation (AF).

\begin{tabular}{|c|c|c|c|c|c|c|}
\hline & $\begin{array}{l}\text { No AF } \\
(\mathrm{N}=55)\end{array}$ & $\begin{array}{l}\text { Any AF } \\
(N=61)\end{array}$ & $\begin{array}{c}\text { Paroxysmal/persistent } \\
\text { AF } \\
(\mathrm{N}=18)\end{array}$ & $\begin{array}{l}\text { Long-standing/ } \\
\text { permanent } A F \\
(N=43)\end{array}$ & $\mathbf{P}^{*}$ & $\mathbf{P} \dagger$ \\
\hline MR degree & & & & & 0.146 & 0.013 \\
\hline Moderate & $2(3.6 \%)$ & $5(8.2 \%)$ & $4(22.2 \%)$ & $1(2.3 \%)$ & & \\
\hline Moderate-severe & $11(20.0 \%)$ & $20(32.8 \%)$ & $3(16.7 \%)$ & $17(39.5 \%)$ & & \\
\hline Severe & $42(76.4 \%)$ & $36(59.0 \%)$ & $11(61.1 \%)$ & $25(58.1 \%)$ & & \\
\hline \multicolumn{7}{|l|}{ Type of MR (Carpentier classification) } \\
\hline I & 27 (49.1\%) & $29(47.5 \%)$ & $10(45.5 \%)$ & $19(36.5 \%)$ & 1.0 & 0.396 \\
\hline II & $5(9.1 \%)$ & $16(26.2 \%)$ & $6(33.3 \%)$ & $10(23.3 \%)$ & 0.028 & 0.028 \\
\hline IIIa & $15(27.3 \%)$ & $11(18.0 \%)$ & $5(27.8 \%)$ & $6(14.0 \%)$ & 0.270 & 0.230 \\
\hline IIIb & $1(1.8 \%)$ & $1(1.6 \%)$ & $1(5.6 \%)$ & 0 & 1.0 & 0.423 \\
\hline LV ejection fraction (\%) & $\begin{array}{l}35.0 \%(30.0 \% \\
48.0 \%)\end{array}$ & $\begin{array}{l}35.0 \%(30.0 \% \\
50.0 \%)\end{array}$ & $38.5 \%$ (30.0\%; 55.0\%) & $35.0 \%(30.0 \% ; 45.0 \%)$ & 0.998 & 0.697 \\
\hline $\begin{array}{l}\mathrm{LV} \text { end-diastolic volume index (mL/ } \\
\left.\mathrm{m}^{2}\right)\end{array}$ & $96(75 ; 122)$ & $84(73 ; 109)$ & $81(61 ; 104)$ & $84(76 ; 109)$ & 0.131 & 0.189 \\
\hline $\begin{array}{l}\mathrm{LV} \text { end-systolic volume index }(\mathrm{mL} / \\
\left.\mathrm{m}^{2}\right)\end{array}$ & $53(42 ; 80)$ & $52(38 ; 69)$ & $45(27 ; 66)$ & $52(40 ; 72)$ & 0.811 & 0.337 \\
\hline Vena contracta (mm) & $9(7 ; 12)$ & $9(7 ; 11)$ & $9(7 ; 11)$ & $8(7 ; 11)$ & 0.726 & 0.662 \\
\hline $\begin{array}{l}\text { Effective regurgitant orifice area } \\
\left(\mathrm{mm}^{2}\right)\end{array}$ & $11(8 ; 12)$ & $10(8 ; 13)$ & $12(8 ; 14)$ & $10(8 ; 12)$ & 0.943 & 0.798 \\
\hline Left atrial volume $\left(\mathrm{mm}^{3}\right)$ & $107(92 ; 138)$ & $109(38 ; 162)$ & $98(40 ; 130)$ & $121(36 ; 169)$ & 0.730 & 0.530 \\
\hline TAPSE (mm) & $17(14 ; 20)$ & $16(13 ; 20)$ & $17(13 ; 20)$ & $16(13 ; 20)$ & 0.287 & 0.564 \\
\hline $\begin{array}{l}\text { Systolic pulmonary artery pressure } \\
\text { (mm Hg) }\end{array}$ & $50(41 ; 58)$ & $45(37 ; 55)$ & $45(30 ; 55)$ & $48(40 ; 55)$ & 0.321 & 0.455 \\
\hline Moderate-severe or severe TR & $12(21.8 \%)$ & $10(16.4 \%)$ & $3(16.7 \%)$ & $7(16.3 \%)$ & 0.486 & 0.811 \\
\hline Clips implanted & & & & & 0.334 & 0.031 \\
\hline None & 0 & $1(1.6 \%)$ & 0 & $1(2.3 \%)$ & & \\
\hline 1 & $38(69.1 \%)$ & $36(59.0 \%)$ & $15(83.3 \%)$ & $21(48.8 \%)$ & & \\
\hline$>1$ & $17(30.9 \%)$ & $24(39.3 \%)$ & $3(16.7 \%)$ & $21(48.8 \%)$ & & \\
\hline Procedural success & $55(100 \%)$ & $60(98.4 \%)$ & $18(100 \%)$ & $42(97.7 \%)$ & 1.0 & 0.526 \\
\hline Procedural time (minutes) & $132(90 ; 190)$ & $115(70 ; 164)$ & $128(78 ; 186)$ & $100(65 ; 158)$ & 0.288 & 0.351 \\
\hline
\end{tabular}

$\mathrm{AR}=$ aortic regurgitation; $\mathrm{LV}=$ left ventricular; $\mathrm{MR}=$ mitral regurgitation; TAPSE=Tricuspid annular plane systolic excursion

Table 3: Follow-up echocardiographic features according to the presence and subtype of atrial fibrillation (AF).

\begin{tabular}{|c|c|c|c|c|c|c|}
\hline & $\begin{array}{l}\text { No AF } \\
(N=55)\end{array}$ & $\begin{array}{l}\text { Any AF } \\
(N=61)\end{array}$ & $\begin{array}{c}\text { Paroxysmal/persistent AF } \\
\text { ( } N=18)\end{array}$ & $\begin{array}{l}\text { Long-standing/ } \\
\text { permanent AF (N } \\
=43 \text { ) }\end{array}$ & $\mathbf{P}^{*}$ & $\mathbf{P} \dagger$ \\
\hline MR degree & & & & & 0.654 & 0.832 \\
\hline Less than moderate & $45(81.8 \%)$ & $47(77.1 \%)$ & $14(77.8 \%)$ & $33(76.7 \%)$ & & \\
\hline Moderate & $8(14.6 \%)$ & $12(19.7 \%)$ & $3(16.7 \%)$ & $9(20.9 \%)$ & & \\
\hline Moderate to severe & $1(1.8 \%)$ & $2(3.3 \%)$ & $1(5.6 \%)$ & $1(2.3 \%)$ & & \\
\hline Severe & $1(1.8 \%)$ & 0 & 0 & 0 & & \\
\hline Decrease in MR degree & $51(92.7 \%)$ & $54(88.5 \%)$ & $16(88.9 \%)$ & $38(88.4 \%)$ & 0.535 & 0.688 \\
\hline Increase in LV ejection fraction (\%) & $0(0 ; 5.0)$ & $0(-3.0 ; 4.0)$ & $1.0(-3.0 ; 3.0)$ & $0(-2.0 ; 4.0)$ & 0.321 & 0.552 \\
\hline $\begin{array}{l}\text { Decrease in LV end-diastolic volume } \\
\left(\mathrm{mL} / \mathrm{m}^{2}\right)\end{array}$ & $4(0 ; 23)$ & $4(-2 ; 22)$ & $16(-2 ; 24)$ & $4(0 ; 19)$ & 0.905 & 0.696 \\
\hline $\begin{array}{l}\text { Decrease in } \mathrm{LV} \text { end-systolic volume } \\
\left(\mathrm{mL} / \mathrm{m}^{2}\right)\end{array}$ & $2(-3 ; 11)$ & $5.5(-2 ; 15)$ & $2(-3 ; 17)$ & $6(-2 ; 12)$ & 0.543 & 0.830 \\
\hline Decrease in vena contracta $(\mathrm{mm})$ & $5(3 ; 8)$ & $5(3 ; 7)$ & $3(3 ; 5)$ & $5(4 ; 7)$ & 0.600 & 0.753 \\
\hline
\end{tabular}




\begin{tabular}{|c|c|c|c|c|c|c|}
\hline $\begin{array}{l}\text { Decrease in effective regurgitant } \\
\text { orifice area }\left(\mathrm{mm}^{2}\right)\end{array}$ & $5(3 ; 7)$ & $5(4 ; 12)$ & $4(4 ; 10)$ & $9(4 ; 28)$ & 0.610 & 0.778 \\
\hline $\begin{array}{l}\text { Increase in mean mitral valve } \\
\text { gradient (mm Hg) }\end{array}$ & $2(2 ; 3)$ & $2(2 ; 3)$ & $3(1 ; 3)$ & $2(2 ; 3)$ & 0.906 & 0.882 \\
\hline Decrease in left atrial volume $\left(\mathrm{mm}^{3}\right)$ & $-4(-20 ; 5)$ & $0(-1 ; 27)$ & $5(0 ; 27)$ & $0(-5 ; 29)$ & 0.061 & 0.156 \\
\hline Increase in TAPSE & $0(-4 ; 1)$ & $0(-2 ; 0)$ & $0(-1 ; 0)$ & $0(-3 ; 2)$ & 0.867 & 0.986 \\
\hline $\begin{array}{l}\text { Decrease in systolic pulmonary artery } \\
\text { pressure (mm Hg) }\end{array}$ & $11(0 ; 25)$ & $5(0 ; 15)$ & $8(0 ; 14)$ & $5(0 ; 15)$ & 0.091 & 0.219 \\
\hline Decrease in TR degree & $16(29.1 \%)$ & $12(19.7 \%)$ & $4(22.2 \%)$ & $8(18.6 \%)$ & 0.280 & 0.493 \\
\hline
\end{tabular}

$\mathrm{AR}=$ aortic regurgitation; $\mathrm{LV}=$ left ventricular; $\mathrm{MR}=$ mitral regurgitation; TAPSE=Tricuspid annular plane systolic

Table 4: Clinical outcomes according to the presence and subtype of atrial fibrillation (AF).

\begin{tabular}{|c|c|c|c|c|c|c|}
\hline & $\begin{array}{l}\text { No AF } \\
(\mathrm{N}=55)\end{array}$ & $\begin{array}{l}\text { Any AF } \\
(\mathrm{N}=61)\end{array}$ & $\begin{array}{c}\text { Paroxysmal/persistent } \\
\text { AF }(\mathrm{N}=18)\end{array}$ & $\begin{array}{c}\text { Long-standing/permanent } \\
\text { AF }(N=43)\end{array}$ & $\mathbf{P}^{*}$ & $\mathrm{P} \dagger$ \\
\hline \multicolumn{7}{|l|}{ In-hospital follow-up } \\
\hline Total hospital stay (days) & $5(5 ; 7)$ & $6(5 ; 9)$ & $6(5 ; 8)$ & $7(5 ; 10)$ & 0.074 & 0.199 \\
\hline Final disposition & & & & & 0.477 & 0.694 \\
\hline Discharge home & $53(96.4 \%)$ & $58(95.1 \%)$ & $17(94.4 \%)$ & $41(95.4 \%)$ & & \\
\hline Transfer to other facility & $1(1.8 \%)$ & 0 & 0 & 0 & & \\
\hline Death & $1(1.8 \%)$ & $3(4.9 \%)$ & $1(5.6 \%)$ & $2(4.7 \%)$ & & \\
\hline Acute kidney injury & $2(3.6 \%)$ & $2(3.3 \%)$ & $2(11.1 \%)$ & 0 & 1.0 & 0.111 \\
\hline Bleeding & 0 & $2(3.3 \%)$ & 0 & $2(4.7 \%)$ & 0.497 & 0.274 \\
\hline \multicolumn{7}{|l|}{ Cumulative follow-up* } \\
\hline Follow-up duration (months) & $6(6 ; 11)$ & $7(6 ; 12)$ & $12(7 ; 14)$ & $6(6 ; 12)$ & 0.578 & 0.744 \\
\hline Death & $4(10.3 \%)$ & $11(26.8 \%)$ & $3(30.0 \%)$ & $8(25.8 \%)$ & 0.085 & 0.130 \\
\hline Myocardial infarction & 0 & 0 & 0 & 0 & 1.0 & 1.0 \\
\hline Stroke & 0 & 0 & 0 & 0 & 1.0 & 1.0 \\
\hline Mitral valve replacement & $1(2.6 \%)$ & 0 & 0 & 0 & 0.487 & 1.0 \\
\hline Rehospitalization for heart failure & $1(2.6 \%)$ & $3(7.3 \%)$ & 0 & $3(9.7 \%)$ & 0.616 & 0.343 \\
\hline $\begin{array}{l}\text { Death or rehospitalization for heart } \\
\text { failure }\end{array}$ & $5(12.8 \%)$ & $14(34.2 \%)$ & $3(30.0 \%)$ & $11(35.5 \%)$ & 0.035 & 0.069 \\
\hline Major adverse event $\dagger$ & $8(20.5 \%)$ & $17(41.5 \%)$ & $5(50.0 \%)$ & $12(38.7 \%)$ & 0.055 & 0.101 \\
\hline Improvement in NYHA class & $20(51.3 \%)$ & $25(61.0 \%)$ & $7(70.0 \%)$ & $14(45.2 \%)$ & 0.499 & 0.428 \\
\hline
\end{tabular}

*limited to the 80 patients ( 39 with no AF group, 41 in the any AF group, 10 in the paroxysmal/persistent AF group, and 31 in the permanent AF group) eligible for $\geq 6$-month follow-up; †composite of death, myocardial infarction, stroke, mitral valve replacement, acute kidney injury, or bleeding

Significant mitral regurgitation is an important cardiovascular condition, [1-2] and in many ways it is the final common pathway of several different cardiac conditions [6]. Degenerative mitral regurgitation is typically due to abnormalities in valve leaflets, whereas functional mitral regurgitation is typically due to cardiac and annulus enlargement. However, both mechanisms may often coexist. Another condition that is often present concomitantly with mitral regurgitation and that may actually contribute to its severity is atrial fibrillation [12]. By definition, atrial fibrillation entails the loss of the atrial systole with its favorable impact on atrial empting and ventricular filling. Moreover, recent data have highlighted that atrial systole (both electrical and mechanical) is important to maximize the efficiency of left ventricular systole while minimizing the likelihood of backflow to the atrium [9]. Indeed, atrial fibrillation leads to uneven atrial contractions which may set the condition for annulus enlargement (at least in relative terms) and asymmetric leaflet movement. All these phenomena explain why patients with atrial fibrillation are at higher risk of developing mitral regurgitation, and, when significant mitral regurgitation is present, atrial fibrillation may be associated with poorer outcomes [13].

While surgical repair is the gold standard treatment in patients with significant mitral regurgitation, MitraClip implantation offers a minimally invasive alternative with acceptable efficacy in patients at high operative risk [1-2]. Indeed, the impact of atrial fibrillation in patients undergoing MitraClip implantation has been already appraised in the pivotal EVEREST II trial comparing cardiac surgery versus TMVR [4]. Specifically, Hermann et al found that atrial fibrillation was present in 45 (26\%) subjects randomized to MitraClip and 27 (30\%) patients randomized to surgery [10]. Atrial fibrillation was associated with older age, a 


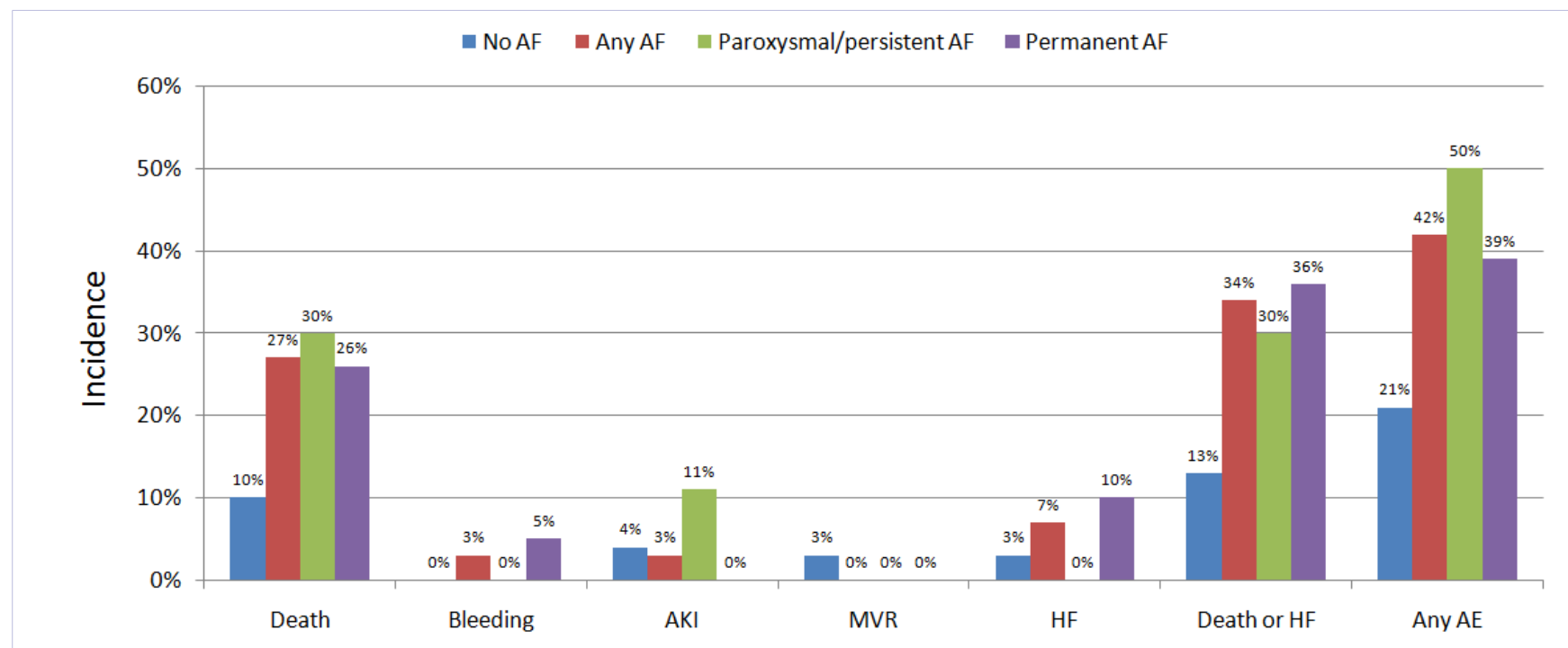

Figure 1: Incidence of adverse events (AE) during follow-up. $\mathrm{AF}$ = atrial fibrillation; $\mathrm{AKI}=$ acute kidney injury; $\mathrm{HF}=$ rehospitalizations for heart failure; MVR = mitral valve replacement.

history of myocardial infarction, prior pace-maker or implantable cardioverter-defibrillator implantation, lower left ventricular ejection fraction, and more common use of vasodilators. In addition, those with atrial fibrillation had a higher likelihood of functional mitral regurgitation and larger atria. Despite these differences, procedural duration, success rate and number of implanted clips were similar irrespective of cardiac rhythm (all $p>0.05$ ). However, atrial fibrillation was associated with longer intensive care or hospital stay. Long-term follow-up showed conversely similar rates of adverse events, but patients with atrial fibrillation had less pronounced reductions in end-diastolic volume and end-systolic volume, were less likely to be pauci- or asymptomatic, or with less than moderate mitral regurgitation. Nonetheless, quality of life scores were similar irrespective of the presence of atrial fibrillation.

We hereby provide complementary evidence in support of TMVR with MitraClip in patients with or without atrial fibrillation, by showing that, when considering real-world subjects with atrial fibrillation, they were also more likely to report prior pacemaker or implantable cardioverter-defibrillator implantation, were less likely to have dilated or ischemic cardiomyopathy, had more severe functional limitation, had higher average operative risk, were less likely to have severe mitral regurgitation at baseline, had more commonly Carpentier type II (i.e. due to prolapse) mitral regurgitation, and required more often the implantation of more than one MitraClip. This latter difference may be due to many synergistic factors, such as the severity of the regurgitation, the size of the left atrium, the presence of prolapse as main cause of regurgitation, or the irregular beating making accurate grasping of the leaflets challenging. No other significant baseline or procedural differences were found. Notably, the fact that atrial fibrillation was associated with more severe functional compromise at baseline was not unexpected, as loss of atrial systole may clearly lead to less optimal left ventricular filling and ensuing ejection. Regarding the reasons for the evident decrease in functional class at follow-up with MitraClip among patients with atrial fibrillation, we have no firm data to explain this phenomenon. We may however speculate that, for the very same reason spelled out just above, improving mitral continence may lead to more evident functional and symptomatic benefits in patients with atrial fibrillation. Another explanation is that patients receiving MitraClip were then followed more intensively and managed more carefully, also with pharmacologic therapy.

The most evident similarity between our work and the EVEREST II substudy on atrial fibrillation, [10] include the fact that patients with atrial fibrillation in both reports had more frequently a history of prior arrhythmia device implantation. Conversely, some associations were reported only by Hermann et al, including older age, more common prevalence of prior myocardial infarction, worse systolic function, more common use of vasodilators, and more common prevalence of functional mitral regurgitation. Conversely, in our registry we found some unique associations between atrial fibrillation and non-dilated/ ischemic cardiomyopathy, more severe functional limitation, higher operative risk, less severe degree of regurgitation, more common prevalence of degenerative mitral regurgitation, and more common need for more than one MitraClip.

The fact that all clinical events were similar in patients with versus without atrial fibrillation with the exception of the composite of death or rehospitalizations for heart failure, which was more common in subjects with atrial fibrillation, should be viewed with caution given the potential for both type II and type I error. In addition, there is an apparent discrepancy between the significant difference in the risk of death or rehospitalizations, and the non-significant difference for major adverse events (which by definition did not include rehospitalizations). However, these findings are in keeping with established data suggesting that atrial fibrillation is an incrementally detrimental prognostic factor in patients with mitral regurgitation [13]. Accordingly, patients with 
atrial fibrillation should not be denied MitraClip implantation, as it appears associated with favorable early and mid-term results. Yet, clinicians should bear in mind that these patients may be at higher risk of adverse events during follow-up and thus merit intensive and careful post-procedure management. Another important therapeutic avenue is offered by atrial fibrillation ablation, which may prove synergic with MitraClip implantation in reducing the risk of repeat hospitalizations. Indeed, in patients without prohibitive surgical risk, cardiac surgery offers both mitral valve repair and ablation within a single procedure.

The focused comparison between subjects with longstanding/permanent versus paroxysmal/persistent atrial fibrillation suggest that those belonging to the former group tend to have a higher surgical risk score, more severe mitral regurgitation, and more need for multiple MitraClips. However, these baseline and procedural differences seem to yield similar clinical and echocardiographic outcomes.

Limitations of this work include the retrospective and observational design, the limited follow-up, and the participation of a limited number of institutions [14,15]. Indeed, in the more comprehensive ACCESS-EU study of MitraClip implantation, the prevalence of atrial fibrillation was even higher (68\%) than hereby reported. In addition, diagnosis and case definition of atrial fibrillation was based on 12-lead EKG and clinical history, rather than on prolonged home or hospital EKG monitoring. Accordingly, information bias in defining the presence or absence of atrial fibrillation and the specific subtype of atrial fibrillation cannot be discarded altogether. In addition, few patients underwent cardiac resynchronization therapy, largely owing to the low prevalence of left bundle branch block. We did not serially appraise atrial volumes and function. Thus, future trials are needed to appraise the impact of MitraClip on such important players in the outlook of atrial fibrillation.

In conclusion, MitraClip can be implanted for TMVR safely and effectively even in patients with atrial fibrillation. Despite similar baseline features, subjects with atrial fibrillation undergoing MitraClip implantation may be at increased risk of follow-up events. Careful follow-up and medical management are thus mandatory in such patients, irrespective of the subtype of atrial fibrillation.

\section{Conflicts of Interest}

Dr. Giordano has consulted, lectured and proctored for Abbott Vascular. Dr. Biondi-Zoccai has consulted and lectured for Abbott Vascular.

\section{Acknowledgements}

Dr. Biondi-Zoccai was, at the time of the preparation of this manuscript, the Congdon Visiting Scholar at the VCU Pauley Heart Center, Virginia Commonwealth University, Richmond, VA, USA.

\section{References}

1. De Bonis M, Maisano F, La Canna G, Alfieri O. Treatment and management of mitral regurgitation. Nat Rev Cardiol 2011; 9:133-46. doi: 10.1038/nrcardio.2011.169.
2. Maisano F, Taramasso M, Cioni M, Buzzatti N, Denti P, Colombo A, et al. Review of the MitraClip clinical evidence. Minerva Cardioangiol. 2012; 60(1):85-93.

3. Feldman T1, Wasserman HS, Herrmann HC, Gray W, Block PC, Whitlow $\mathrm{P}$, et al. Percutaneous mitral valve repair using the edge-toedge technique: six-month results of the EVEREST Phase I Clinical Trial. J Am Coll Cardiol. 2005; 46(11):2134-40.

4. Feldman T, Foster E, Glower DD, Kar S, Rinaldi MJ, Fail PS, et al. Percutaneous repair or surgery for mitral regurgitation. N Engl J Med. 2011 Apr 14;364(15):1395-406. doi: 10.1056/NEJMoa1009355.

5. Nickenig G, Estevez-Loureiro R, Franzen O, Tamburino C, Vanderheyden M, Lüscher TF, et al. Percutaneous Mitral Valve Edgeto-Edge Repair: In-Hospital Results and 1-Year Follow-Up of 628 Patients of the 2011-2012 Pilot European Sentinel Registry. J Am Coll Cardiol. 2014; 64(9): 875-84. doi: 10.1016/j.jacc.2014.06.1166.

6. Silbiger JJ. Anatomy, mechanics, and pathophysiology of the mitral annulus. Am Heart J. 2012; 164(2): 163-76. doi: 10.1016/j. ahj.2012.05.014.

7. Pai RG, Varadarajan $P$, Tanimoto M. Effect of atrial fibrillation on the dynamics of mitral annular area. J Heart Valve Dis 2003; 12: 31-7.

8. Kihara T, Gillinov AM, Takasaki K, Fukuda S, Song JM, Shiota M, et al. Mitral regurgitation associated with mitral annular dilation in patients with lone atrial fibrillation: an echocardiographic study. Echocardiography 2009; 26: 885-9. doi: 10.1111/j.15408175.2009.00904.x

9. Gertz ZM, Raina A, Saghy L, Zado ES, Callans DJ, Marchlinski FE, et al. Evidence of atrial functional mitral regurgitation due to atrial fibrillation: reversal with arrhythmia control. J Am Coll Cardiol. 2011; 58(14): 1474-81. doi: 10.1016/j.jacc.2011.06.032.

10. Herrmann HC, Gertz ZM, Silvestry FE, Wiegers SE, Woo YJ, Hermiller J, et al. Effects of atrial fibrillation on treatment of mitral regurgitation in the EVEREST II (Endovascular Valve Edge-to-Edge Repair Study) randomized trial. J Am Coll Cardiol 2012; 59: 1312-9. doi: 10.1016/j. jacc.2011.12.023.

11. Giordano A, Indolfi C, Ferraro P, Corcione N, Messina S, Mongiardo A, et al. Implantation of more than one MitraClip in patients undergoing transcatheter mitral valve repair: friend or foe? J Cardiol Ther 2014; 1: 133-7.

12. Andrade J, Khairy P, Dobrev D, Nattel S. The clinical profile and pathophysiology of atrial fibrillation: relationships among clinical features, epidemiology, and mechanisms. Circ Res. 2014; 114(9): 1453-68. doi: 10.1161/CIRCRESAHA.114.303211.

13. Grigioni F, Avierinos JF, Ling LH, Scott CG, Bailey KR, Tajik AJ, et al. Atrial fibrillation complicating the course of degenerative mitral regurgitation: determinants and long-term outcome. J Am Coll Cardiol 2002; 40: 84-92.

14. Biondi-Zoccai G, Romagnoli E, Agostoni P, Capodanno D, Castagno D, D'Ascenzo F, et al. Are propensity scores really superior to standard multivariable analysis? Contemp Clin Trials. 2011; 32(5): 731-40. doi: 10.1016/j.cct.2011.05.006.

15. Maisano F, Franzen O, Baldus S, Schäfer U, Hausleiter J, Butter C, et al. Percutaneous mitral valve interventions in the real world: early and 1-year results from the ACCESS-EU, a prospective, multicenter, nonrandomized post-approval study of the MitraClip therapy in Europe. J Am Coll Cardiol. 2013; 62(12): 1052-61. doi: 10.1016/j. jacc.2013.02.094. 